\title{
Comparative Study of Risk Factors Among the Male and Female Patients with Acute Myocardial Infarction Admitted in CCU of Sahid Gangalal National Heart Centre
}

\author{
Raut R, * K.C. MB, * Sharma D, * Rajbhandari S, ${ }^{\star}$ Baidya SG, ${ }^{*}$ Dhungana $M,{ }^{*}$ Pradhan $M$, , Shrestha $P$, \\ Bajracharya $M^{*}$ \\ *Shahid Gangalal National Heart Centre
}

Corresponding Author: Dr. Roshan Raut, Shahid Gangalal National Heart Centre, Bansbari, Kathmandu, Nepal, Tel: 00977-1-4371322, 00977-1-4371374, Fax 00977-1-4371123

\begin{abstract}
The role of major cardiovascular risk factors in the development of coronary artery disease (CAD) is well established and is fairly similar in both sexes. However, CAD is markedly more common in male than in female, and this is due to more risk factors, especially smoking and dyslipidemia, in male. In this study, we aim to investigate the five major risk factors as defined by ACC-AHA namely, advancing age, smoking, hypertension, diabetes and dyslipidemia, in the MI patients admitted in CCU, SGNHC from Jan 1 to June 30th 2008 and to compare whether the association of those risk factors with CAD risk is similar in male and female. There were altogether $283 \mathrm{MI}$ patients, Male $208(73 \%)$ and Female 75 (27\%). Advancing age was the most common comprising $85.2 \%$ followed by smoking $55.5 \%$, Hypertension $48.1 \%$, Dyslipidemia $47 \%$ and Diabetes $24.7 \%$. Smoking, dyslipidemia and advancing age were significantly more common in male. Male patients have significantly more risk factors than female. There was trend towards the greater number of high total cholesterol and low HDL in male patients. Advancing age (Male 45 yrs, Female $55 \mathrm{yrs}$ ) is the commonest risk factor of CAD. Smoking and dyslipidemia (especially high total cholesterol and low HDL) are significantly more common in male which might have contributed markedly to the excess CAD risk in males.
\end{abstract}

Keywords : Risk factors, Acute myocardial Infarction

\section{INTRODUCTION}

The role of major cardiovascular risk factors in the development of coronary artery disease (CAD) is well established. ${ }^{1}$ The "Statement for Healthcare Professionals From the American Heart Association and the American College of Cardioloogy" ${ }^{2}$ states that the major and independent risk factors for CAD are cigarette smoking of any amount, elevated blood pressure, elevated serum total cholesterol and low density lipoprotein cholesterol (HDL-C), diabetes mellitus, and advancing age. The quantitative relationship between these risk factors and CAD risk has been elucidated by the Framingham Heart Study ${ }^{3}$ and other studies.

The role of major cardiovascular risk factors in the development of CAD is markedly more common in male than in female. ${ }^{4-6}$ Literature shows that CAD incidence is 3 times higher in male compared with female. 7 Reasons for the sex difference in CAD risk are not fully understood. In the Prospective Follow Up Study of 14786 Middle-Aged Men and Women in Finland conducted by Pekka Jousilahti et. AI, ${ }^{7}$ about $45 \%$ of the excess CAD risk of men was associated with the sex differences in cardiovascular risk factors. The difference in the total cholesterol and HDL, and smoking rate, contributed markedly to the excess CAD risk of men. Thus, in our study, we aim to investigate the major risk factors in MI patients admitted in CCU and to compare whether the association of those risk factors with CAD risk is similar in male and female.
Although there are also some other CAD risk factors associated with increased risk for $\mathrm{CAD}$, their causative, independent, and quantitative contributions to CAD have not been well documented. So, we did not analyze those risk factors in our study.

\section{OBJECTIVE}

The objective of this study was to compare the association of the major risk factors with CAD risk in male and female.

\section{Materials And Methods}

All the MI patients (ST elevation MI and Non-ST elevation MI) admitted in CCU of Shahid Gangalal National Heart Centre from Jan 1 to June 30th 2008 were included in the study. Patients diagnosed as Unstable Angina were excluded from CCU as some of the low risk unstable angina might simply have had non-specific chest pain and not CAD.

\section{Data Collection}

Data regarding age, type of $\mathrm{Mi}$, Cad risk factors and lipid profile were obtained from hospital registry.

\section{Defining Cardiovascular risk factors:}

Cardiovascular risk factors have been defined according to American College of Cardiology Key Data Elements and 
Definitions for Measuring the Clinical Management and Outcomes of Patients with Acute Coronary Syndromes. 8

1. Advancing age: Male 45 yrs, Female 55 yrs

2. Smoking: History confirming cigarette smoking

3. Dyslipidemia: History of dyslipidemia diagnosed and/ or treted by a physician. Or meets the criteria of National Cholesterol Education Program Criteris:

a. Total cholesterol greater than $200 \mathrm{mg} / \mathrm{dl}$ $(5.18 \mathrm{mmol} / \mathrm{l})$; or

b. Low-density liprotein (LDL) greater than or equal to $130 \mathrm{mg} / \mathrm{dl}(3.37 \mathrm{mmol} / \mathrm{l})$; or

c. High density lipoprotein (HDL) less than $40 \mathrm{mg} /$ $\mathrm{dl}(1.04 \mathrm{mmol} / \mathrm{l})$.

4. Hypertension: Hypertension as documented by:

a. History of hypertension diagnosed and treated with medication, diet, and/or exercise

b. Blood pressure greater than $140 \mathrm{mmHg}$ systolic or $90 \mathrm{mmHg}$ diastolic on at least 2 occasions

c. Current use of antihypertensive pharmacological therapy

5. Diabetes: History of diabetes, regardless of duration of disease, need for antidiabetic agents, or a fasting blood sugar greater than $7 \mathrm{mmol} / \mathrm{l}$ or $126 \mathrm{mg} / \mathrm{dl}$.

\section{RESULTS}

There were altogether 283 MI patients, Male 208 (73\%) and Female 75 (27\%). Mean age of male patients was $59.4 y r s$ and female was $64.8 y$ rs. on the basis of prevalence of risk factors, advancing age was the most common comprising $85.2 \%$ followed by smoking $55.5 \%$, Hypertension $48.1 \%$, Dyslipidemia $47 \%$ and Diabetes $24.7 \%$ (Table 1 )

\section{Table 1: Demographic features of MI patients}

\begin{tabular}{l|l} 
Total Cholesterol & $4.3 \mathrm{mg} / \mathrm{dl}$ \\
\hline Triglyceride & $1.63 \mathrm{mg} / \mathrm{dl}$ \\
\hline HDL & $1.0 \mathrm{mg} / \mathrm{dl}$ \\
\hline LDL & $2.5 \mathrm{mg} / \mathrm{dl}$ \\
\hline High TG & $36.4 \%$ \\
\hline Low HDL & $32.2 \%$ \\
\hline High TC & $19.1 \%$ \\
\hline High LDL & $16.3 \%$ \\
\hline Advanced age & $85.2 \%$ \\
\hline Smoking & $55.5 \%$ \\
\hline Hypertension & $48.1 \%$ \\
\hline Dyslipidemia & $47 \%$ \\
\hline Diabetes & $24.7 \%$ \\
\hline &
\end{tabular}

\section{Comparison of CAD risk factors in Male and Female}

Smoking, dyslipidemia and advancing age were significantly more common in male (Table 2). Male patients have significantly more risk factors than female (table 3 ).
Table 2. Comparison of CAD risk factors

\begin{tabular}{l|l|l|l|} 
Male (\%) Female (\%) P value \\
\hline Advanced Age & 87.9 & 77.3 & 0.03 \\
\hline Smoking & 61.5 & 38.6 & 0.001 \\
\hline Hypertension & 46.1 & 53.3 & 0.34 \\
\hline Dyslipidemia & 50.9 & 36.0 & 0.03 \\
\hline Diabetes & 22.1 & 32.0 & 0.11 \\
\hline
\end{tabular}

\section{Comparison of Lipid profile:}

Although there was no significant difference in the mean lipid profile level between male and female, Hypertriglyceridemia was significantly more common in male than female and there was trend towards the greater no. of high total cholesterol and low HDL in male patients (Table 4).

\section{DISCUSSION}

CAD risks were clearly associated with advancing age. Smoking, hypertension and dyslipidemia were

\begin{tabular}{l|l|l|l}
\hline Table 3. comparison of risk factors burden. \\
\hline Risk factors & Male(\%) & Female(\%) & P value \\
\hline No & 0.5 & 4.0 & \\
\hline One & 9.6 & 16 & \\
\hline Two & 33 & 33 & $<0.05$ \\
\hline Three & 37.5 & 33 & \\
\hline Four & 16.3 & 12.0 & \\
\hline
\end{tabular}

Table 4. Comparison of Lipid profile and type of

dyslipidemia.

\begin{tabular}{|c|c|c|c|}
\hline & Male(\%) & Female(\%) & $P$ value \\
\hline $\begin{array}{l}\text { Total cholesterol } \\
(\mathrm{mg} / \mathrm{dl}\end{array}$ & 4.4 & 4.2 & NS \\
\hline TG (mg/dl) & 1.6 & 1.5 & NS \\
\hline HDL (mg/dl) & 1.01 & 1.04 & NS \\
\hline $\mathrm{LDL}(\mathrm{mg} / \mathrm{dl})$ & 2.6 & 2.5 & NS \\
\hline High TC (\%) & 21.6 & 12 & 0.08 \\
\hline High TG (\%) & 40.3 & 25.3 & 0.025 \\
\hline Low HDL (\%) & 35.0 & 24.0 & 0.08 \\
\hline High LDL (\%) & 17 & 23 & 0.4 \\
\hline
\end{tabular}

also very common in $\mathrm{MI}$ patients comprising $55 \%, 48 \%$ and $47 \%$ respectively, similar to previous study conducted in Nepalese population. 10,11 MI incidence was 3 times higher in male compared with female in our study (73\%vs $27 \%)$. This result is consistent with previous studies.7

Smoking and dyslipidemia, which are also the modifiable risk factors, 9 were significantly more common in male than female., ${ }^{4,7}$ there was significant greater number of CAD risk factors in male than female (Table 3). There was trend towards the greater number of male patients with high total 
cholesterol and low HDL. Our this result is consistent with the various previous studies including the study conducted by Pekka Jousilahti et. $\mathrm{Al}^{7}$ this difference in the dyslipidemia and smoking rate have contributed markedly to the excess CAD risk of men. As smoking and dyslipidemia are the modifiable risk factors, smoking cessation and controlling lipid levels would greatly help in decreasing CAD risk in male. In our study, hypertension and diabetes, a part of metabolic syndrome, were common in female than male but were not statistically significant probably due to small sample size. Apart from this, Hypertridemia, which is also a minor CAD risk factor, was more common in male than female.

Advancing age (Male 45 yrs, Female 55 yrs) is the commonest risk factor of CAD. Smoking and dyslipidemia (especially high total cholesterol and low HDL) are significantly more common in male which might have contributed markedly to the excess CAD risk of men.

\section{CONCLUSION}

\section{REFERENCES}

1. The Pooling Project Research Group. Relationship of blood pressure, serum cholesterol, smoking habit, relative weight, and ECG abnormalities to incidence of major coronary events: final report of the Pooling Project. Dallas, Tex: American Heart Association Monograph No. 60, 1978.

2. Statement for Healthcare Professionals From the American Heart Association and the American College of Cardiology. Journal of the American College of Cardiology. Vol. 38, No. 7, 2001

3. National Heart, Lung, and Blood Institute. Framingham Heart Study. Available at: http://www.nhlbi.nih.gov/ about/framingham/. Accessed June 6, 2004.

4. WHO MONICA Project (Prepared by Tunstall-Pedoe H, Kuulasmaa K, Amouyel P, Arveliler D, Rajakangas A-M, Pajak A). Myocardial Infarction and coronary deaths in the World Health Organization MONICA
Project: registration procedures, event rates, and casefatality rates in 38 populations from 21 countries in four continents. Circulation. 1994;90:583-612.

5. Jackson R, Chambless L, Higgins M, Kuulasmaa K, Wijnberg L, Williams D (WHO MONICA Project, and ARIC Study). Sex difference in ischaemic heart disease mortality and risk factors in 46 communities: an ecologic analysis. Cardiovasc Risk Factors. 1997;7:43-54.

6. The Pooling Project Research Group. Relationship of blood pressure, serum cholesterol, smoking habit, relative weight, and ECG abnormalities to incidence of major coronary events: final report of the Pooling Project. Dallas, Tex: American Heart Association Monograph No.60, 1978.

7. Pekka jousilahti, Erkki Vartiainen, Jaakko Tuomilehto and PekkaPuska Sex, Age,Cardiovascular Risk Factors, and Coronary Heart Disease: A Prospective FollowUpstudy of 14786 Middle-Aged Men and Women in Finland.circulation 1999;99;1165-1172

8. 8.American College of Cardiology Key Data Elements and Definations for Measuring the Clinical Management and Outcomes of Patients with Acute Coronary Syndromes A Report of the American College of Cardiology Task Force on Clinical Data Standards (Acute Coronary Syndromes Writing Committee) Journal of the American College of Cardiology Vol. 38, No. 7, 2001

9. National Cholesterol Education Program (NCEP) Expert Panel on Detection, Evaluation, and Treatment of High Blood Cholesterol in Adults (Adult Treatment Panel III). Third Report of the National Cholesterol Education Program (NCEP) Expert Panel on Detection, Evaluation, and Treatment of High Blood Cholesterol in Adults (Adult Treatment Panel III) final report. Circulation. 2002;106:3143-3421.

10. Karki DB, Neupane A, Pradhan B, et al. Lipid levels in Nepalese population. Kathmandu Univ Med J 2004:2:349-353.

11. K.C. Man Bdr, Rajbhandari S, Sharma D et al. Distribution of Risk Factors with Acute Coronary Syndrome-A Hospital Based Study. Journal of Nepal Medical Association 2003,42:216 - 219 